and management. Dermatol Ther 2006; 19:202-209.

4. Lucky AW, Biro FM, Huster GA, Leach AD, Morrison JA, Ratterman J. Acne vulgaris in premenarchal girls. An early sign of puberty associated with rising levels of dehydroepiandrosterone. Arch Dermatol 1994;130:308-314.

5. Lucky AW. A review of infantile and pediatric acne. Dermatology 1998;196:95-97.

6. Plewig G, Kligman AM. Acne and rosacea. 2nd ed. Berlin: Springer-Verlag, 1993:674-675.

7. Sardana K, Sharma RC, Sarkar R. Seasonal variation in acne vulgaris--myth or reality. J Dermatol 2002;29:484-488.

8. Hancox JG, Sheridan SC, Feldman SR, Fleischer AB Jr. Seasonal variation of dermatologic disease in the USA: a study of office visits from 1990 to 1998. Int J Dermatol 2004;43: 6-11.

9. Karciauskiene J, Valiukeviciene S, Gollnick H, Stang A. The prevalence and risk factors of adolescent acne among schoolchildren in Lithuania: a cross-sectional study. J Eur Acad Dermatol Venereol 2014;28:733-740.

10. Thiboutot D, Del Rosso JQ. Acne vulgaris and the epidermal barrier: is acne vulgaris associated with inherent epidermal abnormalities that cause impairment of barrier functions? Do any topical acne therapies alter the structural and/or functional integrity of the epidermal barrier? J Clin Aesthet Dermatol 2013;6:18-24.

\title{
Squamous Cell Carcinoma on the Fingers of Orthopedic Surgeon Induced by Occupational Radiation Exposure
}

\author{
Hee Seong Yoon, Ji Hye Heo, Si Hyub Lee, Jeonghyun Shin, Gwang Seong Choi, Ji Won Byun \\ Department of Dermatology, Inha University School of Medicine, Incheon, Korea
}

Dear Editor:

Recently, fluoroscopy is useful for diagnosis and treatment and its usage is increasing in the treatment of pain, orthopedic surgery and interventional radiology. The occupational radiation exposure of physicians is also increasing and the hand is the most exposed area. Radiodermatitis of physicians caused by occupational radiation exposure has been reported ${ }^{1}$, but there is few report of the development of squamous cell carcinoma (SCC). We describe an orthopedic surgeon with multiple SCCs on the fingers occupationally exposed to radiation.

A 49-year-old man presented with painful crusted necrotic plaques and scale widely distributed in the both fingers 2 years ago (Fig. $1 \mathrm{~A} \sim \mathrm{E}$ ). He smoked $5 \sim 6$ packs of tobacco every day. He was an orthopedic surgeon and repeatedly exposed to radiation because of frequent use of fluoroscopy. For 11 years, he performed an average of 700 cases of percutaneous vertebral augmentation and 70,000 cases of nerve block per year without radiation shielding gloves. The skin biopsy showed atypical squamous cells invading into dermis forming sheet and individual keratinization (Fig. 2). Magnetic resonance imaging of the right hand suspected bone invasion in the right index finger (Fig. $1 \mathrm{H})$. Chest computed tomography revealed slightly enlarged lymph nodes in both axilla; however, they appeared benign. We diagnosed him with SCC and pre-

Received January 5, 2018, Revised April 2, 2018, Accepted for publication April 15, 2018

Corresponding author: Ji Won Byun, Department of Dermatology, Inha University School of Medicine, 27 Inhang-ro, Jung-gu, Incheon 22332, Korea. Tel: 82-32-890-2238, Fax: 82-32-890-2236, E-mail: piggy1981@hanmail.net ORCID: https://orcid.org/0000-0003-0317-6725

This is an Open Access article distributed under the terms of the Creative Commons Attribution Non-Commercial License (http://creativecommons.org/ licenses/by-nc/4.0) which permits unrestricted non-commercial use, distribution, and reproduction in any medium, provided the original work is properly cited.

Copyright (c) The Korean Dermatological Association and The Korean Society for Investigative Dermatology 

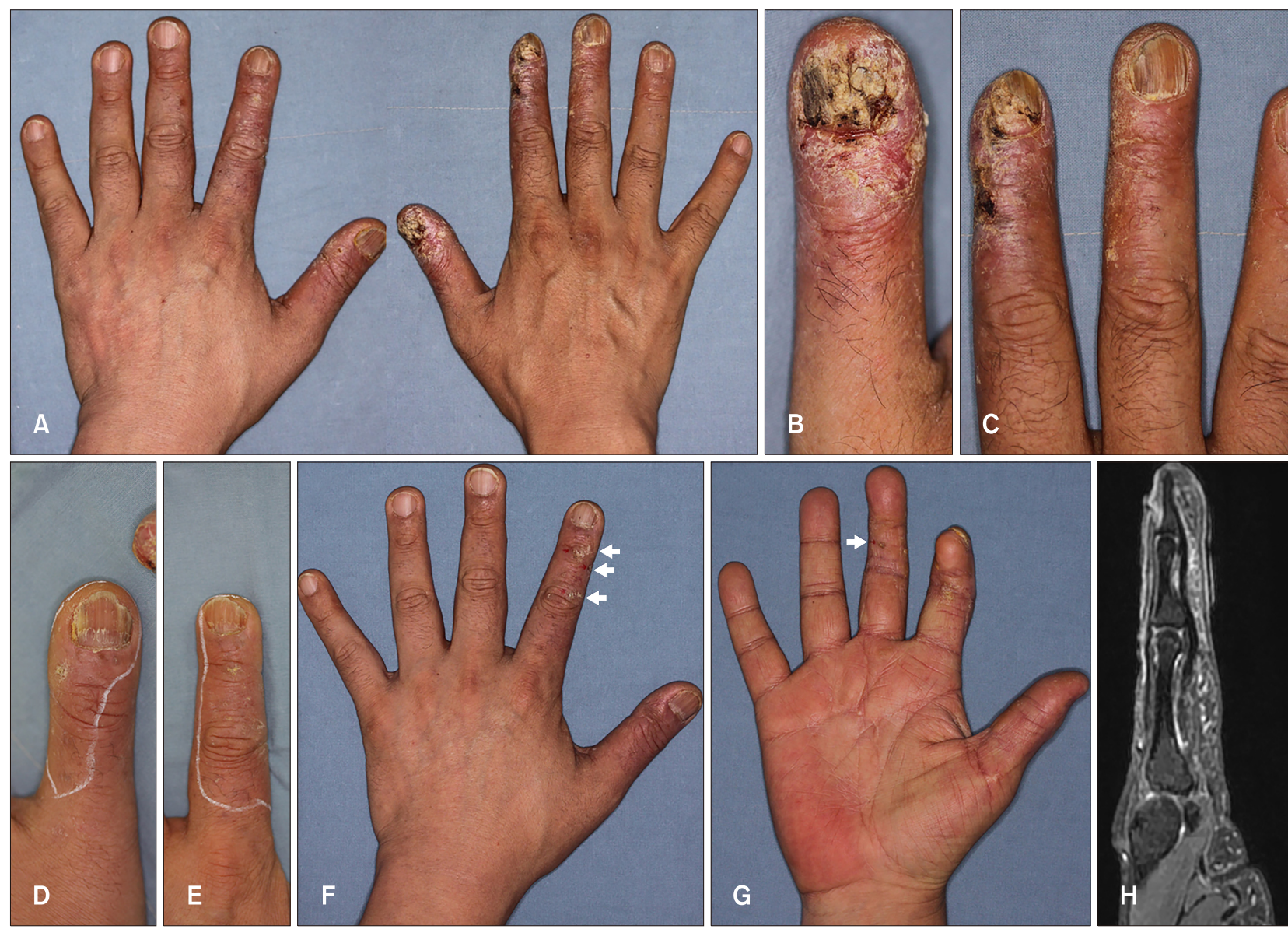

Fig. 1. Painful crusted necrotic plaques and scale widely distributed in the right thumb, index, and 3 rd finger, and left thumb and index finger. Each figure is as follows: (A) Both hands (B) right thumb (C) right index and 3rd finger (D) left thumb (E) left index finger. And photographs after 17 months of follow-up. Each figure is as follows: (F) Dorsal side of the left hand. There were three SCC lesions on the left index finger (arrows). (G) Ventral side of the right hand. There was a SCC lesion on the right third finger (arrow). (H) Right hand MRI image. On the T2 weighted image, SCC invasion is suspected in the medial cortex of the mid phalange and the marrow of the distal phalange of the right index finger. SCC: squamous cell carcinoma, MRI: magnetic resonance imaging.

scribed multidisciplinary cancer care. For the right thumb and index finger, the SCC lesions were widely excised. The distal phalange of the right index finger, which had a high possibility of bone involvement, was partially severed leaving a 6-mm of distal phalange, and the defect was repaired with a free flap. Mohs micrographic surgery (MMS) and a full thickness skin graft (FTSG) was performed on the left thumb. All fingers suspected of skin cancer in situ due to chronic radiation dermatitis were treated with ingenol mebutate. During 17 months of follow-up, he often wore protective gloves and continued to work. However, new SCC lesions of the right middle, left index finger appeared (Fig. 1F, G). MMS and FTSG was performed for those lesions. He is under observation without recurrence until 25 months later.

The effects of radiation exposure on the skin was described by the International Commission on Radiological
Protection in $2010^{2}$. The annual equivalent dose is 500 $\mathrm{mSv}$ to the $\mathrm{skin}^{2}$. Direct beam contact with fluoroscopy causes radiation exposure of $40 \mathrm{mSv}$ per minute, and no deep eye radiation exposure was observed at a distance of $91.4 \mathrm{~cm}$ from the fluoroscope ${ }^{3}$. The skin effects of radiation are divided into acute and chronic changes, depending on the time period from the exposure ${ }^{4}$. Chronic changes include epidermal thinning, fibrosis, edema, dermal thickening, dyspigmentation, telangiectasia, and dermal necrosis ${ }^{4}$. The risk of cutaneous cancer increases after radiation exposure ${ }^{4}$.

Surgical methods are mainly used for the treatment of SCC. Among the surgical methods, MMS has a $96 \%$ cure rate and is the gold standard ${ }^{5}$. If there is bone involvement, amputation should be performed ${ }^{5}$. Since cancer has been reported up to 50 years after exposure, continuous follow-up observation is needed ${ }^{1}$. There is concern in this case 

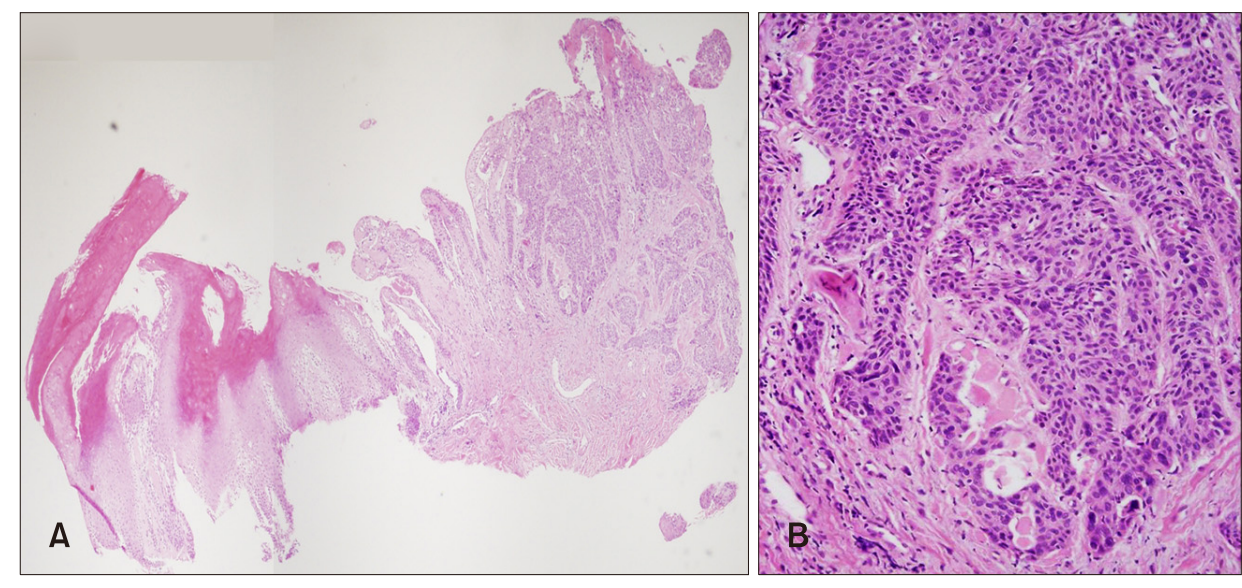

Fig. 2. (A, B) Histopathologic findings of the nail bed of the right thumb (H\&E: A, $\times 40 ; B, \times 200)$. The skin biopsy showed atypical squamous cells invading into dermis forming sheet and individual keratinization. that SCC will recur, so we will continue follow-up. This case demonstrates that physicians should be aware of occupational radiation exposure.

\section{ACKNOWLEDGMENT}

We thank the patient for granting permission to publish this information. This work was supported by the Inha University Research Grant and grants (56990) from the National Research Foundation through the Korean government (NRF-2016R1C1B1014905).

\section{CONFLICTS OF INTEREST}

The authors have nothing to disclose.

\section{ORCID}

Hee Seong Yoon, https://orcid.org/0000-0001-8997-9697

Ji Hye Heo, https://orcid.org/0000-0002-0928-122X

Si Hyub Lee, https://orcid.org/0000-0002-8246-8664

Jeonghyun Shin, https://orcid.org/0000-0002-4995-9533
Gwang Seong Choi, https://orcid.org/0000-0002-5766-0179

ji Won Byun, https://orcid.org/0000-0003-0317-6725

\section{REFERENCES}

1. Shim DM, Kim YM, Oh SK, Lim CM, Kown BT. Radiation induced hand necrosis of an orthopaedic surgeon who had treated a patient with fluoroscopy-guided spine injection. J Korean Orthop Assoc 2014;49:250-254.

2. ICRP. Radiological protection in fluoroscopically guided procedures outside the imaging department. ICRP Publication 117. Ann ICRP 2010;40.

3. Mehlman CT, DiPasquale TG. Radiation exposure to the orthopaedic surgical team during fluoroscopy: "how far away is far enough?". J Orthop Trauma 1997;11:392-398.

4. Hegedus F, Mathew LM, Schwartz RA. Radiation dermatitis: an overview. Int J Dermatol 2017;56:909-914.

5. Dika E, Fanti PA, Patrizi A, Misciali C, Vaccari S, Piraccini BM. Mohs surgery for squamous cell carcinoma of the nail unit: 10 years of experience. Dermatol Surg 2015;41:10151019. 